\title{
Measuring ground deformations with 1-Hz GPS data: the 2003 Tokachi-oki earthquake (preliminary report)
}

\author{
Meilano Irwan ${ }^{1}$, Fumiaki Kimata ${ }^{1}$, Kazuro Hirahara ${ }^{2}$, Takeshi Sagiya ${ }^{1}$, and Atsushi Yamagiwa ${ }^{3}$ \\ ${ }^{1}$ Research Center for Seismology, Volcanology and Disaster Mitigation, Nagoya University, Japan \\ ${ }^{2}$ Department of Earth and Planetary Science, Nagoya University, Japan \\ ${ }^{3}$ Geodetic Observation Center, Geographical Survey Institute, Tsukuba, Japan
}

(Received December 25, 2003; Revised March 3, 2004; Accepted March 8, 2004)

\begin{abstract}
We analyzed 1-Hz GPS data observed at 14 stations of the GPS Earth Observation Network (GEONET) of the Geographical Survey Institute, Japan, associated with the $2003 \mathrm{M}_{J M A} 8.1$ Tokachi-oki earthquake, which occurred at the Kurile Trench. The GPS stations are located $70-240 \mathrm{~km}$ away from the epicenter. GPS data clearly captured rapid co-seismic ground displacements. At a GPS station $70 \mathrm{~km}$ away from the epicenter, coseismic displacements started 15 seconds after the origin time, and after 40 seconds at the stations $240 \mathrm{~km}$ away. Observed displacement amplitude exceeded $20 \mathrm{~cm}$ at GPS sites $240 \mathrm{~km}$ away from the epicenter. Displacement amplitudes attenuate with time and distance from the epicenter, oscillating with periods of 40-60 seconds. We compared the 1-Hz GPS data and displacement seismogram integrated from strong ground motion data, which showed fairly good agreements. In spite of careful screening of 1-Hz GPS data during 30 minutes preceding the main shock, no significant preseismic deformation over $1 \mathrm{~cm}$ in the horizontal components was recorded. 30 second sampling GPS data at 14 sites during 20 hours preceding the main shock did not show any significant pre-seismic deformation, either. These results indicate that pre-seismic strain change, if any, was smaller than $0.5-1.0 \times 10^{-7}$ before the 2003 Tokachi-oki earthquake.
\end{abstract}

Key words: 2003 Tokachi-oki earthquake, 1-Hz GPS measurements, coseismic deformation, preseismic deformation.

\section{Introduction}

A megathrust earthquake of a magnitude 8.1 struck Hokkaido in North Japan at 4:50 on September 26, 2003 (JST). This earthquake occurred $80 \mathrm{~km}$ southeastern off the Erimo Peninsula, on the surface of the subducting Pacific plate, and was named as the 2003 Tokachi-oki earthquake.

Co-seismic displacements up to $1 \mathrm{~m}$ were reported immediately by GPS static analysis from the GPS Earth Observation Network (GEONET) of Geographical Survey Institute, Japan (GSI) (GSI, 2003). Based on GPS displacements and seismic waveforms, a $100 \times 100 \mathrm{~km}$ fault is estimated to have slipped southeastward larger than $5 \mathrm{~m}$ along the interface between the Pacific plate and North American plate (GSI, 2003; Yamanaka and Kikuchi, 2003; Yagi, 2003).

On the other way, pre-slip is suggested from the precise leveling which was executed just before the occurrence of the 1944 Tonankai earthquake (Mogi, 1985; Linde and Sacks, 2002). Thus the detection of pre-slip is a crucial key to a successful earthquake prediction. As the 2003 Tokachi-oki earthquake is the first megathrust earthquake on the plate interface around Japan after the establishment of GEONET, it is very important to discuss whether there was precursory displacement or not. In particular, $1-\mathrm{Hz}$ GPS is expected to play an important role in resolving site displacement just

Copy right (C) The Society of Geomagnetism and Earth, Planetary and Space Sciences (SGEPSS); The Seismological Society of Japan; The Volcanological Society of Japan; The Geodetic Society of Japan; The Japanese Society for Planetary Sciences; TERRAPUB before the main shock.

Developments in the latest GPS measurement technology have enabled us to resolve the ground deformations associated with earthquakes and volcanic activities in more detail. Kinematic GPS is an effective tool for studying rapid deformation associated with dike intrusion or volcanic eruption (Larson et al., 2001, Irwan et al., 2003). 1-Hz GPS measurement can be also applied as an ultra-long period seismograph for earthquake studies (Miyazaki et al., 1997). Moreover, Larson et al. (2003) demonstrated a good agreement between strong ground-motions records integrated to displacement and 1-Hz GPS position data associated with the Denali Fault Earthquake in 2002.

$1-\mathrm{Hz}$ GPS measurement has been in operation at GEONET stations since April 2003. There is a dense network of strong-motion seimograph, called K-NET, by the National Research Institute for Earth Science and Disaster Prevention (NIED). We can easily compare the 1-Hz GPS results with the seismological record. Such a basic study is important in developing 1-Hz GPS measurement technique.

In this paper, we present and discuss the preliminary results of ground deformations detected from 1-Hz GPS data analysis of GEONET associated with the 2003 Tokachi-Oki earthquake.

\section{Methods}

Figure 1 shows locations of GPS sites and epicenter of the main shock of the 2003 Tokachi-oki earthquake. Since we use relative positioning, a reference point is required. 


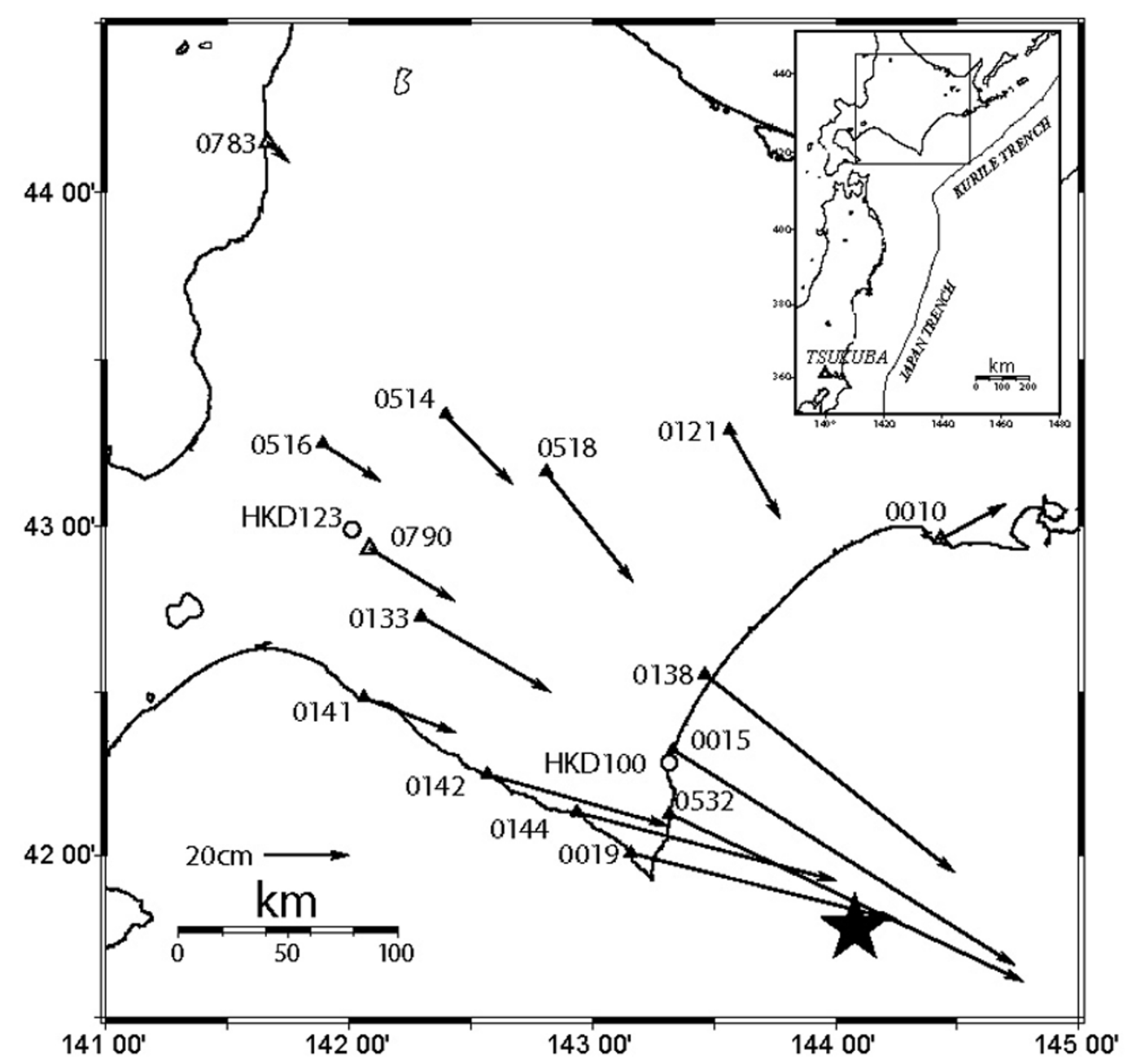

Fig. 1. Location map of GEONET GSI stations in Hokkaido, and epicenter of the 2003 Tokachi-oki earthquake by NIED (2003). Star means the location of main shock. Triangles show the location of the GEONET GSI stations, and fixed stations of 0790 and 0783 are shown as open triangles. Seismic stations discussed in our work are shown as open circles. Coseismic displacements are calculated from Tsukuba GPS station in the index map in the period from 17-27 September 2003.

In kinematic relative positioning, station distance should be short in order to obtain precise results, while the reference point should be located far from the epicenter so that the deformation due to the earthquake is small and to avoid the situation that the reference site is disturbed by seismic waves before the target sites are disturbed. Accordingly, we chose two reference points, stations 0790 and 0783 . Relative to the station 0790 , displacements at stations 0019, 0532, 0144, 0142, 0015, 0141 and 0138, located more south were determined. Displacement at six stations 0121, 0133, 0518, 0790,0514 and 0516 located in the north of 0790 were determined from station 0783. The baseline lengths to the referring station are ranging from $50 \mathrm{~km}$ to $200 \mathrm{~km}$. These GPS stations are located $70 \mathrm{~km}$ to $330 \mathrm{~km}$ away from the earthquake epicenter.

We processed the GPS data with Bernese software version 4.2 software (Hugentobler et al., 2001) using pseudokinematic coordinate estimation sequence, which includes: (1) cycle-slip screening and outlier removal using ionosphere free linear combination (L3) double difference phase residual, (2) ambiguity resolution using wide-lane (L5) and then
L3 single difference. Since the pre-processing software of Bernese does not assume rapid change of baseline, it could happen that phase shift caused by the displacement is erroneously recognized (and edited) as cycle-slip. The similar problem can happen also in the ambiguity resolution.

Unfortunately, at some stations close to the source region, there was a loss of GPS data during several minutes just after the occurrence of the main shock because of some disturbance effects on the telemetry system due to the strong ground motion by the main shock.

We also analyzed the strong motion data recorded by the K-NET. Digital acceleration data were integrated twice in time domain to produce ground displacements (Boore, 2001). There exist baseline offsets in the acceleration data. Though they can not been visibly recognized, they produce clear linear trends in the integrated velocity data and nonstationary final displacements. The strong motion certainly produces the offsets, but the detailed mechanisms affecting instruments have not been revealed. There are, therefore, no universal baseline correction methods that can be applied to any records (Boore et al., 2002). Then, we constrained the 

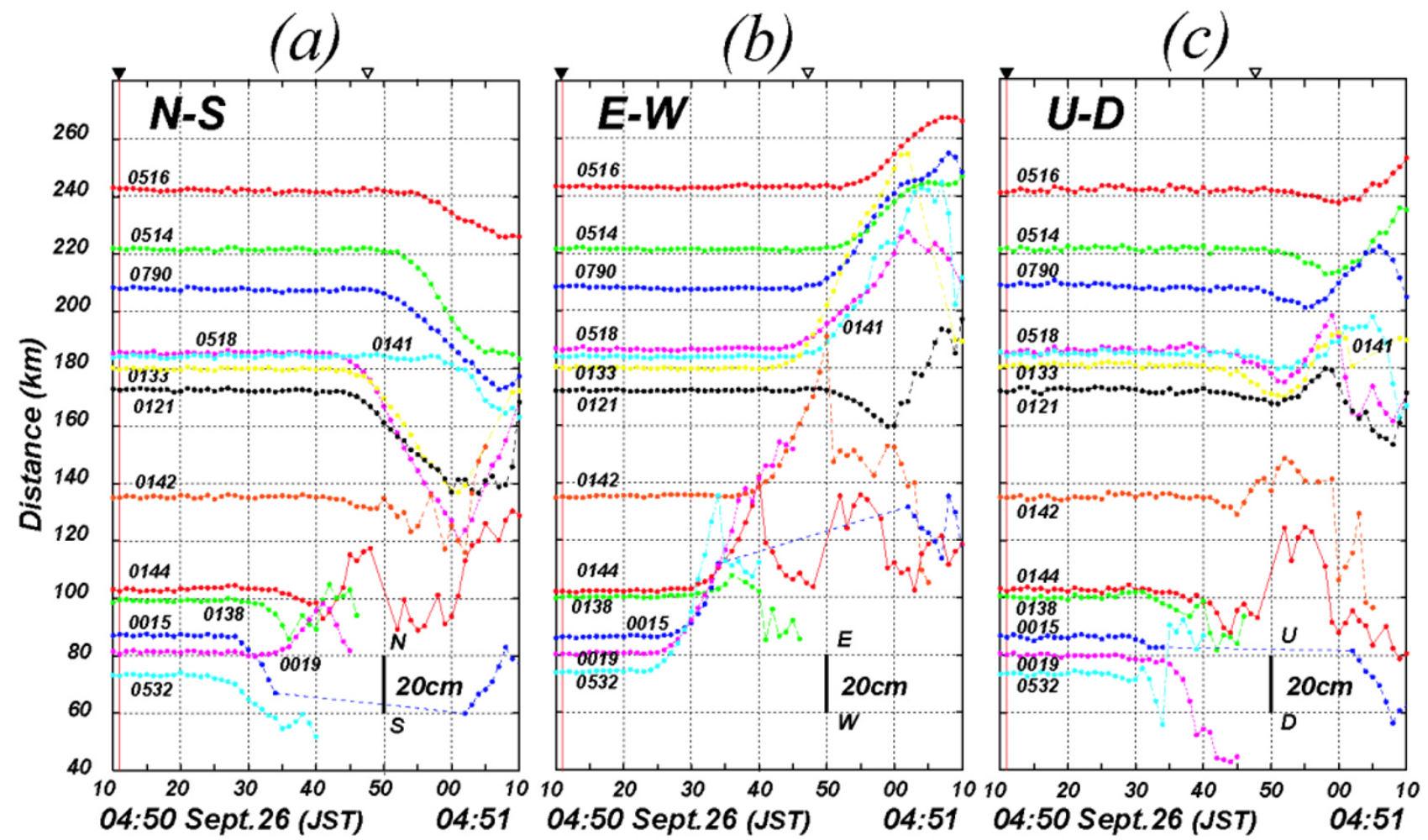

Fig. 2. Time series of site displacements in north-south (a), east-west (b) and up-down (c) components, detected from 1-Hz GPS measurements during the period of 1 minute from 04:50:10, 26 September 2003 (JST). Time series are plotted as functions of distance from the epicenter. The stations within 160 $\mathrm{km}$ from the earthquake epicenter are referred to station 0790, and the further stations are referred to station 0783. Downward solid and open triangles mean the origin time of the earthquake and the estimated onset time of deformation at the fixed station of 0790 , respectively.

integration to agree with surface coseismic displacements, changing several fitting parameters for baseline correction according to Boore (2001).

\section{Result and Discussion}

Figure 2 shows time series of three components of ground displacements from $1-\mathrm{Hz}$ GPS measurements at 13 stations of GEONET during the period of 04:50:10-04:51:10, September 26, 2003 (JST). The plot are vertically aligned with offsets proportional to the epicentral distance of each GPS station. As shown in this figure, each station was displaced south or southwestward as large as $1 \mathrm{~m}$, which is concordant with the static GPS analysis results calculated from daily solution in the period from 17-27 September 2003.

The origin time of the earthquake and the estimated onset time of ground deformation at the fixed station 0790 are inserted in Fig. 2 as the solid and open downward arrows. It is noted that GPS results at stations with reference Station 0790 suffer from the movements of the reference station after the estimated onset time marked by an open downward arrow.

Southeastward displacements exceeded $40 \mathrm{~cm}$ within 10 seconds after the arrival of initial motion even at the distant station where the final displacements were much smaller. Station 0121 is located to the northwest of epicenter, and the displacement was firstly observed westward. The westward displacement is shifting toward east 10 second after.

From Fig. 2, we can clearly identify a propagation of displacement from the epicenter. Propagation velocity is estimated as about $4-5 \mathrm{~km} / \mathrm{sec}$. Furthermore, coseismic dis- placements are clear even at stations far from the epicenter, and the onsets of the displacements in the far field show more gentle than those in the near field.

Figure 3 shows the time series of coseismic displacements in three components at the GPS stations 160-240 km away from the epicenter during 4 minutes from 4:50, September 26 . The origin time of the earthquake and arrival time of displacements at station 0783 estimated from Fig. 2 are shown in the figure as the solid and open downward arrows.

We discuss several characteristics of $1-\mathrm{Hz}$ GPS results shown in Fig. 3. Firstly, southeastward displacements are clearly identified at all the stations. There are two or three deformation pulses during the period of about 60 seconds, which may correspond to the ground shaking of the main shock. Secondly, the deformations are so large that the initial pulses reach $40 \mathrm{~cm}$ or larger, and the displacement amplitudes decreased with time. Furthermore, southwestward displacements and subsidence were detected 30 seconds after the initial pulses.

Although the westward displacement was first observed in the east-west component at station 0121 as mentioned above, eastward displacement is observed as the coseismic deformation, as shown in Fig. 1.

Figure 4 shows a comparison of 1-Hz GPS displacements and those obtained from strong ground motion data. The integration of strong motion accelerogram was conducted with baselines corrections (Boore, 2001). The GPS displacement at $0015(42.3216 \mathrm{~N}, 143.3310 \mathrm{E})$ is compared with the seismic displacement at HKD100 (42.2838N, 143.3158E), and The GPS displacement at $0790(42.9311 \mathrm{~N}, 142.0881 \mathrm{E})$ is com- 


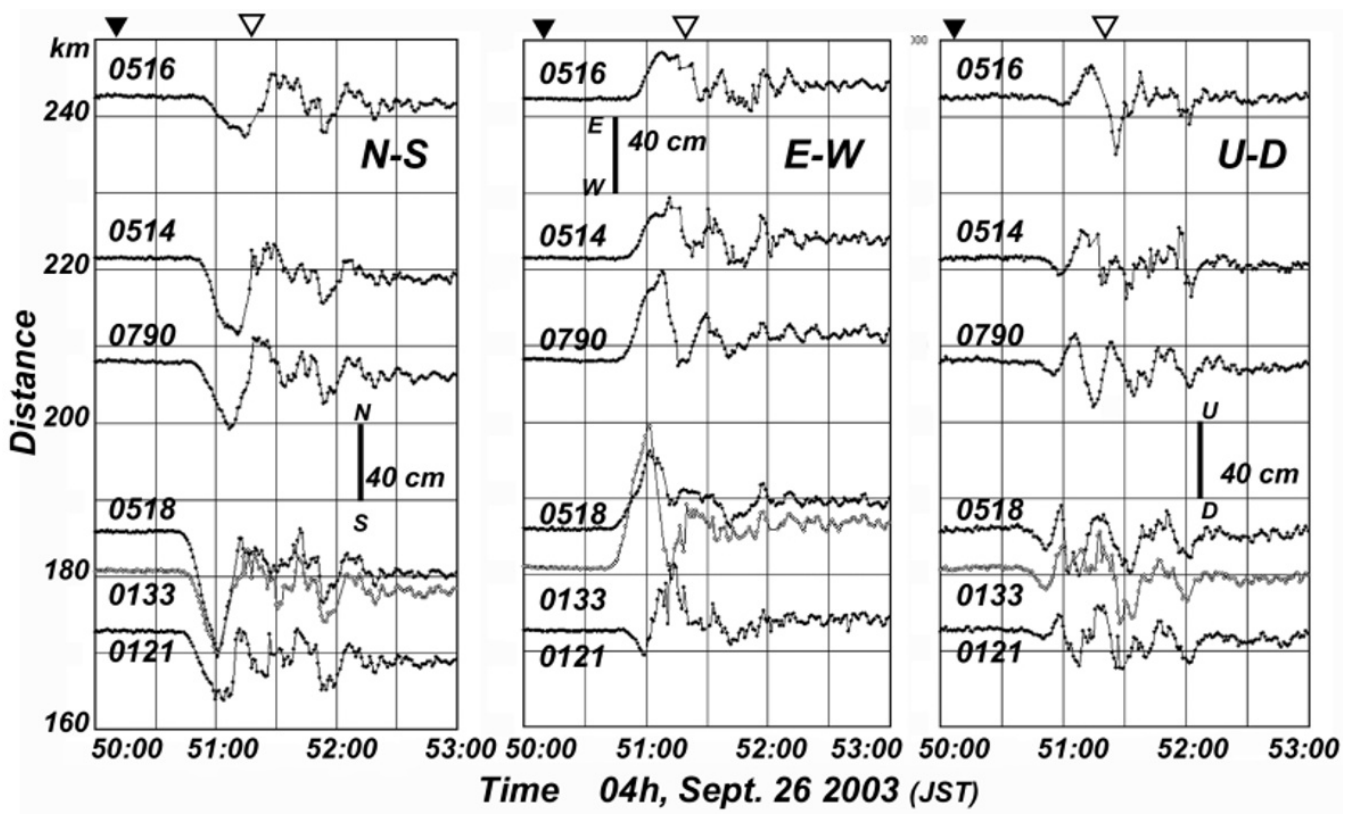

Fig. 3. Time series of site displacements at GPS stations out of $170 \mathrm{~km}$ from the earthquake epicenter referred to station 0783 in the period of 3 minutes from 04:50:00, 26 September 2003 (JST). Time series are plotted as functions of distance from the epicenter. Downward solid and open triangles mean the origin time of the earthquake and the estimated onset time of deformation at the fixed station of 0783 from Fig. 2 , respectively.

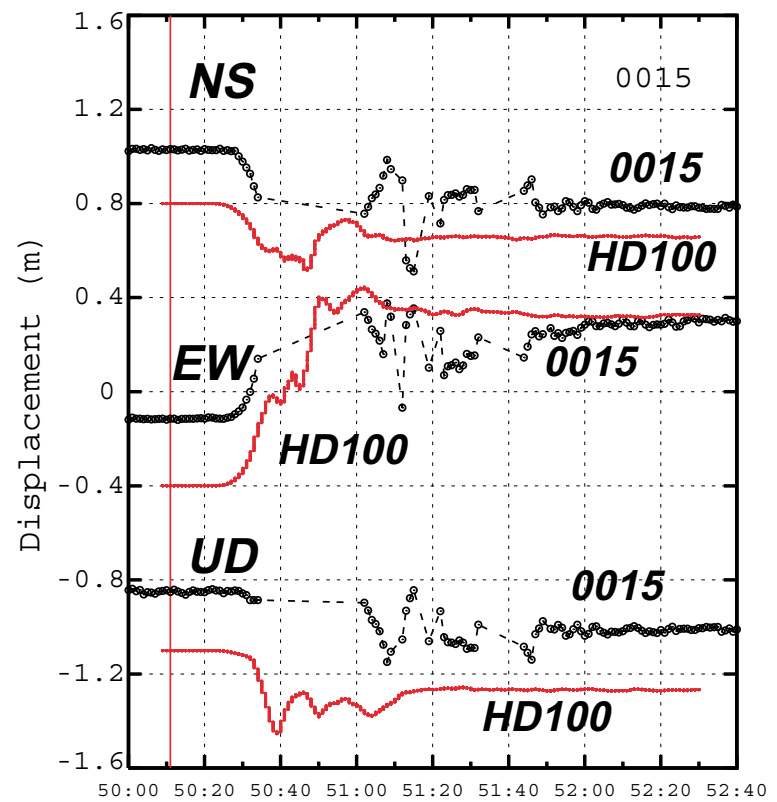

(a)

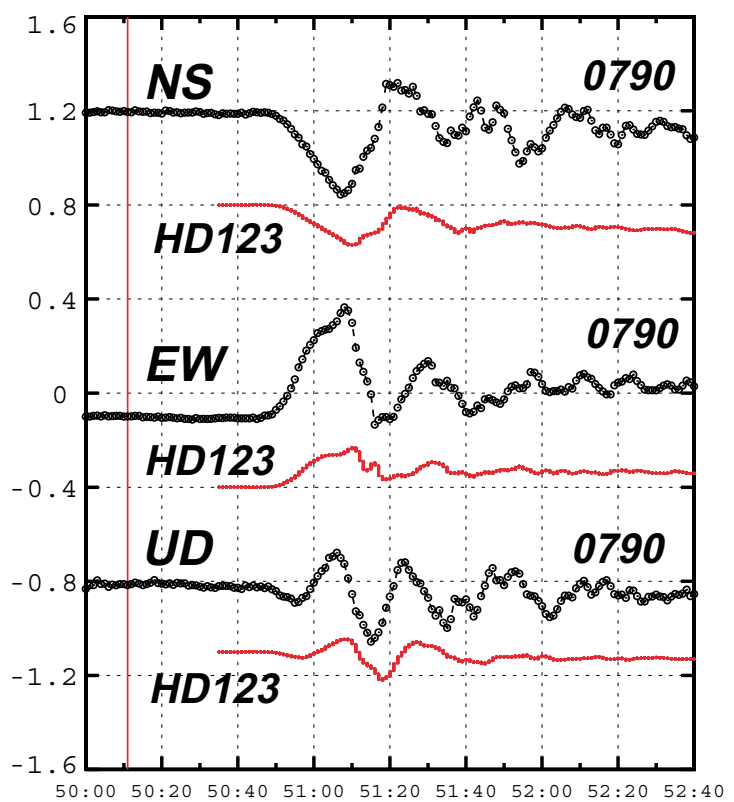

(b)

Fig. 4. Comparison of the displacements estimated from the seismogram and 1-Hz GPS measurements at the Tokachi-oki earthquake. Integrated acceleration seismograms at HKD100 and HKD123 of NIED are indicated by red dots, and the displacements at GPS Stations 0015 and 0790 of GEONET by black ones.

pared with HKD123 (42.9908N, 142.0122E). The distances between above GPS stations and seismic stations are ranging within $10 \mathrm{~km}$.

As shown in Fig. 4, the displacements at HKD123 clearly show the similar time variation as GPS results at 0790 . The same coincidence has already been reported by Larson et al. (2003) for the 2002 Denali Fault Earthquake. Displacements detected by them show a result with a period of about 10 seconds. On the other hand, displacements associated with the 2003 Tokaichi-oki earthquake are characterized by longer period than that of the Denali Fault earthquake. This result may suggest that the source process of the Tokachioki Earthquake was simpler than that of the Denali Fault Earthquake. One problem is that the displacements of three components detected by $1-\mathrm{Hz}$ GPS data are smaller at station 0015, and larger about twice at station 0790. The site conditions are different for GPS and seismic stations, and the baseline corrections in integration of acceleration records 


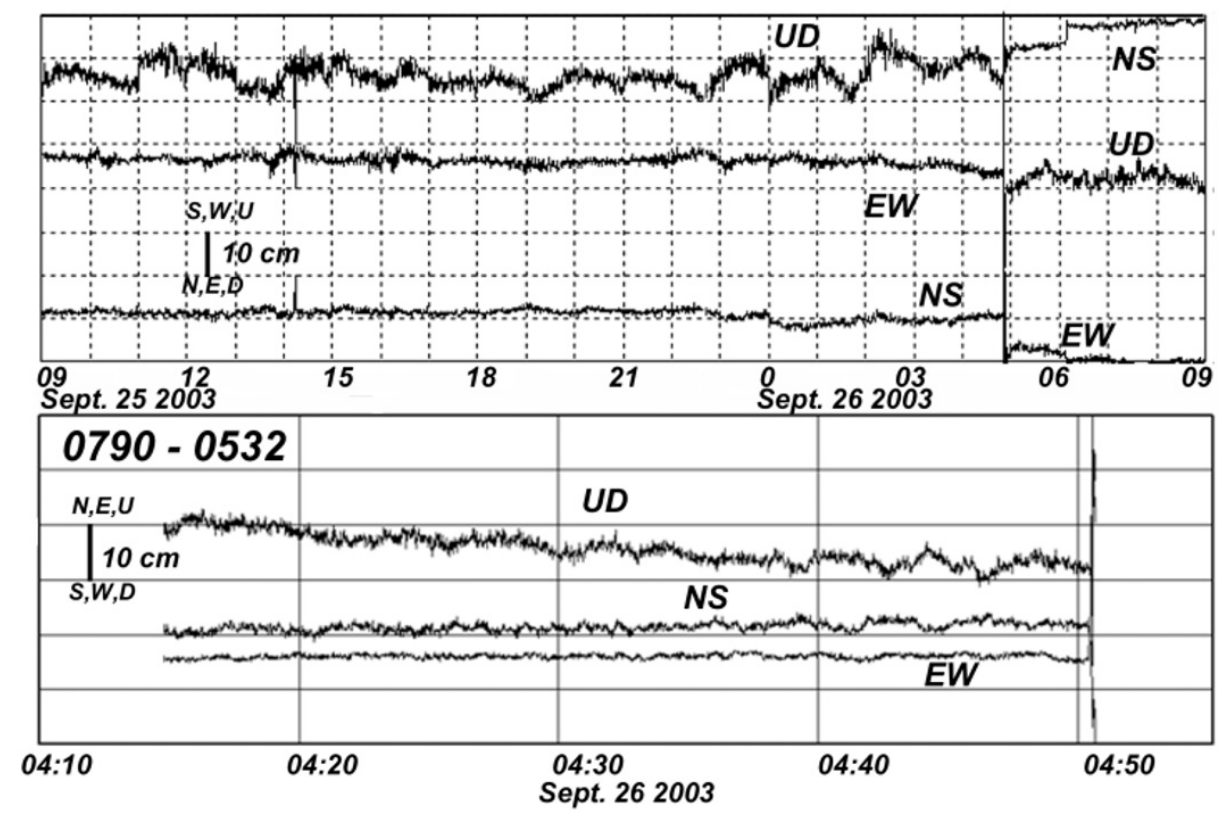

Fig. 5. Time series of site displacements at station 0532 before the 2003 Tokachi-oki earthquake. The 30 -sec data in 20 hours (upper) and the 1-sec data in $30 \mathrm{~min}$ (lower) before the main shock are shown.

may have some problems (Boore et al., 2002). Though we have not yet identified any definite causes, they may produce the observed amplitude differences.

Finally we discuss the pre-seismic deformations. The possible preseismic tilt change of the 1944 Tonankai earthquake was larger than $1 \times 10^{-5}$ radian (Mogi, 1988). We examine the 30- and 1-second GPS data using kinematic GPS analysis. Figure 5 shows the time series of the GPS solution at station 0532 , the nearest $(71 \mathrm{~km})$ from the epicenter. The 30 -second data are analyzed for 20 hours preceding the main shock referring to the station 0010 , and the 1 -second data are analyzed for 30 minutes before the main shock referring to the station 0790. Both of the reference stations are 170-180 $\mathrm{km}$ away from the 0532. From Fig. 5, GPS results showed some fluctuations within $1-2 \mathrm{~cm}$ in the horizontal components, but we cannot detect any significant precursory change of the main shock in these results. Thus we conclude that there was no detectable precursory displacement for the 2003 Tokachi-oki earthquake from GPS observations, at least during 20 hours preceding the main shock. The precursory strain change, if any, should be $0.5-1 \times 10^{-7}$ or smaller. Considering practical noise level of continuous GPS and borehole instruments, we cannot be optimistic about successful detection of precursory signals of such a large earthquake and imminent warning based on those signals. Earthquake prediction experiments in other regions must be carefully reviewed again with this "real" experience.

Acknowledgments. We express gratitude to staff of Research Center for Seismology, Volcanology and Disaster Mitigation, Nagoya University, especially to Professor Naoyuki Fujii. Comments by Takao Tabei and anonymous reviewer significantly improved the quality of the paper.

\section{References}

Boore, D. M., Effect of baseline corrections on displacements and response spectra for several recordings of the 1999 Chi-Chi, Taiwan, earthquake, Bull. Seis. Soc. Am., 91, 1199-1211, 2001.

Boore, D. M., C. D. Stephens, and W. B. Joyner, Comments on baseline correction of digital strong motion data: Examples from the 1999 Hector Mine, California, Earthquake, Bull. Seis. Soc. Am., 92, 1543-1560, 2002. Geographical Survey Institute, Ground deformation in the 2003 Tokachi Oki earthquake, 101st meeting of Coordinating Committee for Earthquake Prediction, 2003.

Hugentobler, U., S. Schafer, and P. Fridez, Bernese GPS Software Version 4.2., Astronomical Institute University of Berne, 515 pp., 2001.

Irwan, M., F. Kimata, N. Fujii, S. Nakao, H. Watanabe, S. Sakai, M. Ukawa, E. Fujita, and K. Kawai, Rapid ground deformation of the Miyakejima volcano on 26-27 June 2000 detected by kinematic GPS analysis, Earth Planets Space, 55, e13-e16, 2003.

Larson, K., P. Cervelli, M. Lisowski, A. Miklius, P. Segall, and S. Owen, Volcano monitoring using GPS I. Filtering strategies, J. Geophys. Res., 106, 19,453, 2001

Larson, K., P. Bodin, and J. Gomberg, Using 1-Hz GPS data to measure deformations caused by the Denali Fault earthquake, Science, 300, 2003.

Linde, A. T. and I. S. Sacks, slow earthquakes and great earthquakes along the Nankai trough, Earth and Planetary Science Letters, 202, 265-275, 2002.

Miyazaki, S., T. Sagiya, T. Tada, and Y. Hatanaka, One Hz sampling GPS as an ultra-long-period seismograph, 1997 AGU Fall Meeting, December 8-12, San Francisco, California, 1997.

Mogi, K., Temporal variation of crustal deformation during the days preceding a thrust-type great earthquake - the 1944 Tonankai earthquake of magnitude 8 in Japan, Pure Appl. Geophys., 122, 765-780, 1985.

National Research Institute for Earth Science and Disaster Prevention, The 2003 Tokaichi-oki Earthquake, http://www.hinet.bosai.go.jp/topics/ tokachi0309/, 2003.

Yagi, Y., Rupture Process for September 262003 Tokachi-oki, Japan, earthquake, http://iisee.kenken.go.jp/staff/yagi/eq/Japan20030926/ japan20030926.html, 2003.

Yamanaka, Y. and M. Kikuchi, Source process of the recurrent Tokachioki earthquake on September 26, 2003, inferred from teleseismic body waves, Earth Planets Space, 55, e21-e24, 2003.

M. Irwan (e-mail: irwan@seis.nagoya-u.ac.jp), F. Kimata, K. Hirahara, T. Sagiya, and A. Yamagiwa 